\title{
Synthetical Evaluation of Performance of Open-ended Stock Funds in China
}

\author{
Jiandong $\mathrm{He}$ \\ Jiaxing Vocational Technical College, Jiaxing, Zhejiang, China, 314036 \\ alto_he@sina.com
}

\begin{abstract}
In this paper, eleven indexes affecting performance of open-ended stock funds are chosen. Then an improved information entropy model with genetic algorithm in which subjective and objective analysis are combined is proposed for synthetically evaluating of performance of funds in China. After that, we calculate the score of 35 funds and their ranking, which reveals that the model is practical.
\end{abstract}

Keywords: open-ended stock funds, entropy method, evaluation, genetic algorithm

\section{Introduction}

As one of the mainstream funds in China's investment market, open-ended stock fund develops at a rapid speed. Hexun.com shows that there are 569 open-ended stock funds, which are the most important investment products favored by investors. Although the number of open-ended stock funds is rising, the performance evaluation remains unchanged-- ROE growth based on single ratio. This paper analyzes the fruits made by foreign and domestic scholars inperformance evaluation, builds a model of synthetical performance evaluation of open-ended stock funds in China. Based on the subjective and objective combined evaluation model, we get the ranking of China's open-ended stock funds in synthetical performance evaluation.

\section{Main Factors Affecting Performance of Funds}

\subsection{Overall Performance}

\subsubsection{ROE}

Computational formula of ROE:

$$
R_{i}=\frac{N A V_{t}-N A V_{t-1}+D_{t}}{N A V_{t-1}}
$$

Where, $R_{i}$ stands for the ROE offund $i$ in period of $t ; N A V_{t}$ and $D_{t}$ stand for the net value and cash dividend of fund $i$.

\subsubsection{Performance Evaluation after Risk Adjusted}

As for evaluation of performance of a fund, only its ROE is not enough. We must consider measuring risk. Treynor ratio model, Sharpe ratio model and Jensen ratio model, called single-factor model of the overall performance evaluation,greatly simplify the complexity of assessing the overall performance of the fund.

Sharp ratio: the average excess return is divided by the standard deviation of this period's earnings[1], which can be calculated as follows: $S_{P}=\left(\overline{R_{P}}-R_{f}\right) / \sigma_{p}$. 
$R_{f}$ is risk-free rate of return, $\sigma_{p}$ is standard deviation of rate of return, which is used to represent the degree of risk

Similar to Sharp ratio, Treynor also measures the excess return per unit of risk, but it is used for systemic risk, but not all risks[2]. The formula is: $T_{P}=\left(\overline{R_{P}}-R_{f}\right) / \beta_{p}$

Jensen ratio is the average yield based on the CAPM calculation, which represents the difference between the actual yield and the CAPM model predicts yield [3]. The computing formula is:

$$
J_{P}=\overline{R_{P t}}-\left[R_{f}+\beta_{p}\left(\overline{R_{m}}-R_{f}\right)\right]
$$

These three ratio models are greatly correlated. Therefore, this paper adopts Jensen ratio to measure the performance after risk adjustment.

\subsection{Fund Risk}

The riskin this paper are standard deviation and $\beta$ coefficient.

\subsubsection{Standard Deviation}

Standard deviation, also known as mean square error, is widely used to measure statistical dispersion in probability statistics. The standard deviation's computing formula of sample fund portfolio is:

$$
\sigma_{p}=\sqrt{\frac{\sum_{t=1}^{n}\left(R_{p t}-\overline{R_{p}}\right)}{n-1}}, \overline{R_{p}}=\frac{\sum_{t=1}^{n} R_{p t}}{n}
$$

Where, $\sigma_{p}$ is the standard deviation, $R_{p t}$ is the real yield of sample fund portfolio, and $\overline{R_{p}}$ is the mean value of sample fund portfolio.

\subsection{2 $\beta$ Coefficient}

$\beta$ coefficient is an important ratio reflecting dynamic changes of one fund or fund portfolio against security market systematic risk[4][5]. The computing formula of $\beta$ coefficient:

$$
\begin{gathered}
\beta_{p}=\frac{\operatorname{cov}\left(R_{p}, R_{m}\right)}{\sigma_{m}^{2}} \\
\sigma_{m}=\sqrt{\frac{\sum_{t=1}^{n}\left(R_{m t}-\overline{R_{m}}\right)}{n-1}}, \operatorname{cov}\left(R_{p}, R_{m}\right)=\frac{\sum_{t=1}^{n}\left(R_{p t}-\overline{R_{p}}\right)\left(R_{m t}-\overline{R_{m}}\right)}{n-1},
\end{gathered}
$$

Where, $\operatorname{cov}\left(R_{p}, R_{m}\right)$ is the covariance between the yield of stock $p$ and market returns; $\sigma_{m}^{2}$ is the variance of the market return, and $\overline{R_{m}}$ is mean of benchmark yield rate of security market. 


\subsection{Ability of Fund Manager}

The ability of fund manager means the ability to screen stocks and select appropriate time.

Ability to grasp appropriate market time refers to the fund manager's ability to make wise judgment on the investment market. When the stock market prospect is promising, the fund manager is able to seize the chance. Through adjusting the portfolio of risky and safe assets, the fund manager can access to higher market gains rate; conversely, the fund manager can take the opposite approach to achieve the purpose of risk aversion. T-M model is to test the portfolio manager's market timing ability[6][7].

$$
R_{P t}-R_{f}=a+b\left(R_{m t}-R_{f}\right)+c\left(R_{m t}-R_{f}\right)^{2}+d
$$

Where, $b$ is the $\beta$ coefficient, $d$ stands for error, and $c$ represents the index of ability to select market timing. If $\mathrm{c}$ is significantly greater than zero, indicating that investors have market timing ability. The greater $\mathrm{c}$ is, the larger the excess return of the fund relative to the market portfolio, indicating the better performance of the fund.

\subsection{Liquidity}

Fund liquidity ratios can be reflected by holdings concentration, industry concentration and securities adjusted efficiency.

\subsubsection{Holdings Concentration}

The index indicates the degree of concentration of the fund's holdings, which is calculated as follows:

$$
z_{1}=\frac{y_{1}}{x_{1}}
$$

Where $x_{1}$ : total net asset value of the fund.

$y_{1}$ : net asset value of $\mathrm{n}$ stocks which are favourite stocks in the fund.

$z_{1}$ : holdings concentration

Here, $n$ may be 3,5 or 10 , we chooses 3 .

\subsubsection{Industry Concentration}

The index indicates the degree of concentration of the fund's holdings, which is calculated as follows:

$$
z_{2}=\frac{y_{2}}{x_{2}}
$$

Where $x_{2}$ : total net asset value of the fund.

$y_{2}$ : net asset of $\mathrm{n}$ industries which are highest favourite industries in the fund.

$z_{2}:$ industry concentration

Here, $\mathrm{n}$ can be 3,5 or 10 , we chooses 3 .

\subsubsection{Securities Adjusted Efficiency}

In this ratio, the spread yield gained from transaction cost per unit is used to represent the efficiency of adjusted security portfolio. The computing formula is 


$$
z_{3}=\frac{y_{3}}{x_{3}}
$$

Where $x_{3}:$ transaction fees

$y_{3}:$ Spread yield of securities.

$z_{3}:$ adjusted securities efficiency

\subsection{Fund-related Expenses}

Fund-related expenses can reflect fund manager's ability in fund management. This paper focuses on the expense ratio per unit revenue and net income per unit cost. Computational formula of expense ratio per unit revenue is

$$
z_{4}=\frac{y_{4}}{x_{4}}
$$

Where $x_{4}$ :total expense.

$y_{4}$ :General income.

$z_{5}$ :Expense ratio per unit revenue.

Computational formula of net income per unit cost is

$$
z_{6}=\frac{y_{6}}{x_{6}}
$$

Where $x_{6}$ : general expense.

$y_{6}:$ Net profit.

$z_{6}:$ net income per unit cost.

Factors affecting fund performance include the overall performance, risk, fund manager's ability, liquidity and expenses. The synthetical evaluation system is

\begin{tabular}{|c|c|c|c|c|}
\hline $\begin{array}{l}\text { Overall } \\
\text { Performance }\left(w_{1}\right)\end{array}$ & Fund $\operatorname{risk}\left(w_{2}\right.$ & $\begin{array}{l}\text { Fund manager's } \\
\text { ability }\left(w_{3}\right)\end{array}$ & Liquidity $\left(w_{4}\right)$ & $\begin{array}{l}\text { Fund-related } \\
\text { expense }\left(w_{5}\right)\end{array}$ \\
\hline $\operatorname{REO}\left(w_{11}\right)$ & $\sigma_{p}\left(w_{21}\right)$ & stock selection $\left(w_{31}\right)$ & $\begin{array}{l}\text { Holding concentration }\left(w_{41}\right) \\
\text { (sum of the first three ) }\end{array}$ & $\begin{array}{l}\text { Income-related } \\
\text { expense rate }\left(w_{51}\right)\end{array}$ \\
\hline Jensen ratio $\left(w_{12}\right)$ & $\beta\left(w_{22}\right)$ & timing selection $\left(w_{32}\right)$ & $\begin{array}{l}\text { Industry allocation }\left(w_{42}\right) \\
\text { (sum of the first three ) } \\
\text { Securities adjustment efficiency( } \\
w_{43} \text { ) }\end{array}$ & $\begin{array}{l}\text { Expense-related yield } \\
\left(w_{52}\right)\end{array}$ \\
\hline
\end{tabular}
established, as shown in Table 1:

Table 1.Synthetical Evaluation System 


\section{Data Standardization}

Before the comprehensive evaluation of fund, first we need to standardize the data and carry out data analysis through the standardized data. Data standardization refers to statistical data indexation. The standardization involves convergent and dimensionless processing.Formula of positive directional indicators on the performance:

$$
x^{\prime}=\frac{x-x_{\min }}{x_{\max }-x_{\min }}
$$

Formula of negative directional indicators on the performance:

$$
x^{\prime}=\frac{x_{\max }-x}{x_{\max }-x_{\min }}
$$

\section{Synthetical Evaluation Model}

On the one hand, evaluation system of performance is subject to subjective factors.In this paper, in order to coordinate the interests of each aspect, the experts mark to construct the subjective constraint of index weight. The method is as follows.

STEP1: build advisory panel. The investors, fund managers and other related stakeholders are to build the advisory panel. The members should take equalization as the principle and each party should voice its opinion as possible as it can.

STEP2: judgment of the importance of indexes. Experts are invited to judge the relative importance of indexes and make records. For instance, if one expert believes that the index of $w_{i}$ is more important than that of $w_{j}$, he should make record as follows.

$w_{i}>w_{j}$, similarly, consultation to all experts may give us the subjective constraints.

STEP3: the structure of subjective constraints. Depending on different expert opinions, the subjective constraints are constructed. If all the experts reach a consensus on the same conditions, their judgment constitutes the constraint condition; if the experts have different views on the same issue, simple majority is taken and opinion of most experts shall be the constraint condition; if the experts fail to give their judgment on two different ratios, no constraint condition shall be constructed, i.e. it is null and void.

On the other hand, information entropy function is constructed.

Information entropy has been widely used in evaluation. Information entropy is defined for a set number of columns:

$$
X=\left\{X_{1}, X_{1} \cdots, X_{n}\right\}\left(X_{i} \geq 0, \sum_{i=1}^{n} X_{i}=1\right), H(X)=-\sum_{i=1}^{n} X_{i} \ln X_{i} \text { is the information }
$$

entropy function of sequence $X, X_{i}$ is the attribute information.

Suppose the amount of funds is $n$, and the amount of indexes is $m$, the benchmark value in the evaluation period is $a_{i j}$, the weight of each index in fund performance evaluation system is $w_{j}$, the method to construct the objective distinction degree of fund performance using information entropy is:

STEP1: construct the synthetical performance equation of the $i$ fund:

$$
B_{i}=\sum_{j=1}^{m} w_{j} a_{i j}
$$

Where, $B_{i}$ is the synthetical performance of a fund.

STEP2: construct the synthetical performance sequence of normalized fund: 


$$
C_{i}=\frac{B_{i}}{\sum_{i=1}^{n} B_{i}} \text { where, the normalized performance of the }{ }^{i} \text { fund is } C_{i} \text { 。 }
$$

STEP3: construct the distinction degree of information entropy.

$$
H(C)=-\sum_{i=1}^{n} C_{i} \ln C_{i}
$$

According to information entropy definition, combining with normalized performance, the information entropy function of synthetical fund performance:

$$
H(C)=-\sum_{i=1}^{n} C_{i} \ln C_{i}
$$

Here, $H(C)$ stands for the information entropy of evaluation results. Obviously, the larger the value of $H(C)$ is, the greater the distinction between the evaluation of the results, indicating the greater the overall performance differences between the various funds. Therefore, $H(C)$ can be the goal of weight solution, getting the optimal weight vector and then evaluate each fund. However, the goal should satisfy the subjective judgment of the experts, so as to enable quantitative evaluation requirements consistent with experts. Thus, the established subjective constraints can jointly construct the nonlinear programming model to optimize the weights.

We selected 4 fund professional investors and 5 investment analysts and they formed a panel of experts and judged the importance of the indicators in the evaluation system. If they have different opinions on the importance of the same group of indicators, the plurality rule will be adopted. If they fail to make judgment, we may consider the importance is unknown and we will use optimizing search to get the weight through optimization algorithm. The following table is a constraint given by experts. The index weights in tables 2-6 are corresponding. ">" indicates the importance of the indicators in the same row is greater than that of the indicators in the line. "-" indicates that the data is not given.

Table 2. Overall Fund Evaluation Index Weight

\begin{tabular}{|l|l|l|l|l|l|}
\hline & $w_{1}$ & $w_{2}$ & $w_{3}$ & $w_{4}$ & $w_{5}$ \\
\hline$w_{1}$ & - & - & - & - & $>$ \\
\hline$w_{2}$ & $>$ & - & - & - & $>$ \\
\hline$w_{3}$ & $>$ & $>$ & - & $>$ & $>$ \\
\hline$w_{4}$ & - & - & - & - & - \\
\hline$w_{5}$ & - & - & - & - & - \\
\hline
\end{tabular}


Table 2. Overall Performance WeightTable 3. Fund Risk Weight

\begin{tabular}{|l|l|l|}
\hline & $w_{11}$ & $w_{12}$ \\
\hline$w_{11}$ & - & - \\
\hline$w_{12}$ & $>$ & - \\
\hline
\end{tabular}

\begin{tabular}{|l|l|l|}
\hline & $w_{21}$ & $w_{22}$ \\
\hline$w_{21}$ & - & - \\
\hline$w_{22}$ & $>$ & - \\
\hline
\end{tabular}

Table4. Fund Manager's Ability Weight

Table 5. Liquidity Weight

\begin{tabular}{|l|l|l|}
\hline & $w_{31}$ & $w_{32}$ \\
\hline$w_{31}$ & - & - \\
\hline$w_{32}$ & $>$ & - \\
\hline
\end{tabular}

\begin{tabular}{|c|c|c|c|}
\hline & $w_{7}$ & $w_{8}$ & $w_{9}$ \\
\hline$w_{7}$ & - & - & $>$ \\
\hline$w_{8}$ & $>$ & - & $>$ \\
\hline$w_{9}$ & - & - & - \\
\hline
\end{tabular}

Table 6. Fund Expenses Weight

\begin{tabular}{|l|l|l|}
\hline & $w_{10}$ & $w_{11}$ \\
\hline$w_{10}$ & - & - \\
\hline$w_{11}$ & - & - \\
\hline
\end{tabular}

Then, synthetical evaluation model is established is

$$
\left\{\begin{array}{l}
\max H(w)=-\sum_{i=1}^{35} \frac{\sum_{j=1}^{11} w_{j} a_{i j}}{\sum_{i=1}^{35} \sum_{j=1}^{11} w_{j} a_{i j}} \ln \frac{\sum_{j=1}^{11} w_{j} a_{i j}}{\sum_{i=1}^{35} \sum_{j=1}^{11} w_{j} a_{i j}} \\
w_{2}>w_{1}, w_{4}>w_{3}, w_{6}>w_{5}, w_{7}>w_{9}, w_{8}>w_{7} \\
w_{3}+w_{4}>w_{1}+w_{2} \\
w_{5}+w_{6}>w_{3}+w_{4} \\
w_{1}+w_{2}>w_{10}+w_{11} \\
w_{5}+w_{6}>w_{7}+w_{8}+w_{9} \\
w_{5}+w_{6}>w_{10}+w_{11} \\
\sum_{j=1}^{11} w_{j}=1
\end{array}\right.
$$




\section{The Solution of the Model}

For the problem mentioned above is an non-linear programming, this paper uses genetic algorithm to solve it $[11,12,13]$. The main steps of the algorithm are following:(1) a set of initial solutions is randomly generated. When the initial chromosomes are randomly generated, a feasibility of detection function for the chromosome is designed in order to ensure that satisfy the constraints. Then, among an initial feasible solution focused group, 200 feasible solutions are randomly selected, and they are regarded as the initial solution group.

(2) the value of fitness function is calculated.Evaluation function is used here as a fitness function, and the probability of next generation is determined through judging the size of fitness. Since this objective function is to seek minimal value, therefore, the smaller the fitness value, the greater the probability of entering the next generation.

(3) Select the object of genetic manipulation and do genetic manipulation to form the next generation groups. Genetic manipulation in simple genetic algorithm could be chosen, cross and mutated. In the selection, this paper adopts fitness proportional selection method and uses the roulette designed by Holland (1975).

(4) returns to (2) and this paper evaluates the new solution of this group.

5) When Algorithm reaches to certain conditions, the calculation ends, or it transfers to (3).

Algorithm keeps ongoing evolution in each generation until the end of evolution when it satisfies the termination criterion, and outputs the optimal solution. This paper, through maximum evolution algebra, this paper sets the termination criterion. When the maximum number of iterations equals to the maximum evolutionary algebra, the algorithm automatically terminates $[14,15]$.Finally, The weight vector is got, as shown in table 2.

Table 2. Weight Vector

\begin{tabular}{|l|l|l|l|l|l|l|}
\hline Index & $w_{1}$ & $w_{2}$ & $w_{3}$ & $w_{4}$ & $w_{5}$ & $w_{6}$ \\
\hline Weight & 0.057255 & 0.07114 & 0.049436 & 0.12634 & 0.14116 & 0.24872 \\
\hline Index & $w_{7}$ & $w_{8}$ & $w_{9}$ & $w_{10}$ & $w_{11}$ & \\
\hline Weight & 0.079465 & 0.061381 & 0.036786 & 0.063953 & 0.06507 & \\
\hline
\end{tabular}

According to Table 2,we calculate the synthetical evaluation score of 35 funds and rank their ranking, as shown in table 3.

Table 3. Synthetical Evaluation Score of 35 Funds and their Ranking

\begin{tabular}{llllll}
\hline $\begin{array}{l}\text { Fund } \\
\text { code }\end{array}$ & $\begin{array}{l}\text { Synthetical } \\
\text { evaluation score }\end{array}$ & Ranking & Fund code & $\begin{array}{l}\text { Synthetical } \\
\text { evaluation } \\
\text { score }\end{array}$ & Ranking \\
\hline 20001 & 0.55247 & 6 & 162605 & 0.54045 & 15 \\
20003 & 0.49943 & 22 & 162703 & 0.58268 & 3 \\
50001 & 0.54801 & 12 & 180003 & 0.48265 & 29 \\
50002 & 0.48697 & 26 & 200002 & 0.50762 & 21
\end{tabular}




\begin{tabular}{llllll}
50004 & 0.50941 & 20 & 202001 & 0.5411 & 14 \\
90001 & 0.54886 & 10 & 206001 & 0.53932 & 16 \\
100020 & 0.48961 & 25 & 210001 & 0.41436 & 35 \\
110002 & 0.58893 & 2 & 213002 & 0.42129 & 33 \\
110005 & 0.551 & 7 & 217001 & 0.43908 & 32 \\
160105 & 0.54719 & 13 & 233001 & 0.45636 & 31 \\
160505 & 0.52786 & 18 & 240001 & 0.58021 & 4 \\
160603 & 0.54883 & 11 & 240005 & 0.49927 & 23 \\
161605 & 0.54887 & 9 & 260101 & 0.55433 & 5 \\
161606 & 0.48552 & 27 & 260104 & 0.63225 & 1 \\
162102 & 0.47386 & 30 & 360001 & 0.53735 & 17 \\
162201 & 0.5126 & 19 & 460001 & 0.4924 & 24 \\
162202 & 0.484 & 28 & 519996 & 0.41789 & 34 \\
162203 & 0.54955 & 8 & & & \\
\hline
\end{tabular}

\section{Acknowledgements}

This paper is supported by scientific research fund of Zhejiang provincial education department, and the fund number is Y201329829.

\section{References}

[1] F. William, "Sharpe", Journal of business, vol. 39, no. 1, (1996).

[2] B. P. S. Murthi, Y. K. Choi and P. Desai, European Journal of Operational Research, vol. 98, no. 2, (1997).

[3] M. C. Jensen, Journal of Finance, vol. 23, no. 2, (1968).

[4] R. Roll, Journal of Finance, vol. 33, (1978).

[5] A. Admati and S. A. Ross, Journal of Business, vol. 58, (1985).

[6] J. L.Treynor and K. K. Mazuy, Harvard Business Review, vol. 44, no. 2, (1966).

[7] M. Grinblatt and S. Titman, Journal of Business, vol. 62, no. 3, (1989).

[8] Z. H. Zou, Y. Yun, J. N. Sun, Journal of Environmental Sciences, vol. 18, no. 5, (2006).

[9] B. D. Fan, China Rural Water and Hydropower, vol. 9, (1998).

[10] D. C. Fang, G. L. Liu and L. P. Zhang, Value Engineering, vol. 2, (2004).

[11] R. Cheng and M. Tsujimura, Computers \& Industrial Engineering, vol. 4, no. 30, (1996).

[12] S. F. Niu and L. Chen, Journal o f Northwest Normal University (Natural Science), vol. 1, no. 47, (2011).

[13] R. Storn and K. Price, International Computer Science Institute, (1995).

[14] T. Back, "Evolutionary algorithm s in theory and practice", Oxford University Press, (1995).

[15] D. E. Goldberg, "Genetic algorithms in search optimization and machine learning", Addison Wesley, (1989). 


\section{Author}

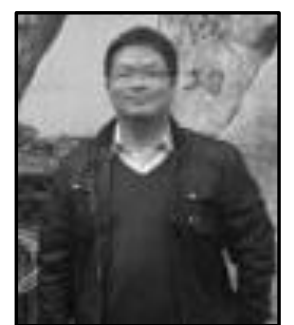

Jiandong He, he isa mathematics teacher of Jiaxing Vocational Technical College in China.Title: lecturer,Degree: the Master in Finance;Key research area: Financial Mathematics. 